\title{
6-Phosphofructo-2-kinase/fructose-2,6-bisphosphatase isoform 3 spatially mediates autophagy through the AMPK signaling pathway
}

\author{
Siyuan Yan ${ }^{1,3}$, Xiaoli Wei ${ }^{2}$, Shanshan $X u^{1,3}$, Hui Sun ${ }^{1,3}$, Weijun Wang ${ }^{1,3}$, Ling Liu ${ }^{1}$, \\ Xuejun Jiang ${ }^{1}$, Yongxiang Zhang ${ }^{2}$ and Yongsheng $\mathrm{Che}^{2}$ \\ ${ }^{1}$ State Key Laboratory of Mycology, Institute of Microbiology, Chinese Academy of Sciences, Beijing 100101, China \\ ${ }^{2}$ State Key Laboratory of Toxicology \& Medical Countermeasures, Beijing Institute of Pharmacology \& Toxicology, Beijing \\ 100850, China \\ ${ }^{3}$ University of Chinese Academy of Sciences, Beijing 100039, China \\ Correspondence to: Yongsheng Che, email: cheys@im.ac.cn \\ Yongxiang Zhang, email: zhangyx@bmi.ac.cn \\ Keywords: PFKFB3, glycolysis, nuclear localization, autophagy, AMPK \\ Received: June 06, $2017 \quad$ Accepted: August 06, $2017 \quad$ Published: September 08, 2017 \\ Copyright: Yan et al. This is an open-access article distributed under the terms of the Creative Commons Attribution License 3.0 \\ (CC BY 3.0), which permits unrestricted use, distribution, and reproduction in any medium, provided the original author and source \\ are credited.
}

\section{ABSTRACT}

6-Phosphofructo-2-kinase/fructose-2,6-bisphosphatase isoform 3 (PFKFB3), is a critical enzyme for glycolysis and highly expressed in cancer cells. It plays an essential role in regulating metabolism, angiogenesis, and inflammation. Although PFKFB3 is involved in modulating autophagy, its regulatory role appears to be either positive or negative, which remains to be clarified. Unlike other PFK-2/FBPase isoforms, PFKFB3 can localize in both nucleus and cytoplasm, leading to the speculation that subcellular localization of PFKFB3 may play a regulatory role in autophagy. Here, we found that either a PFKFB3 inhibitor or PFKFB3 silencing by siRNA, suppressed the basal and the $\mathrm{H}_{2} \mathrm{O}_{2}$-induced autophagy concomitantly with the inhibition of AMPK activity. While overexpression of the wild type PFKFB3 promoted the $\mathrm{H}_{2} \mathrm{O}_{2}$-induced autophagy, the K472/473A mutated PFKFB3, which lost nuclear localizing property, inhibited the autophagic process. Although the K472/473A mutated PFKFB3 stimulated more lactate production, it decreased the activity of AMPK compared to the wild type PFKFB3. Moreover, PFKFB3 similarly regulates the autophagy induced by rasfonin, a fungal secondary metabolite that downregulates the activity of AMPK. Compound $C_{\text {, }}$ a widely used AMPK inhibitor, induced the autophagic process but reduced the $\mathrm{H}_{2} \mathrm{O}_{2}-$ dependent autophagy. Collectively, the data demonstrated that PFKFB3 localizing in nucleus is essential for its regulatory role in autophagy, and PFKFB3 at least positively regulated the $\mathrm{H}_{2} \mathrm{O}_{2}$-induced autophagy through the AMPK signaling pathway, which likely played dual roles in the process.

\section{INTRODUCTION}

Metabolism of cancer cells supports continuous cell growth and proliferation in tumor microenvironment [1]. Cancer cells are prone to high rate of aerobic glycolysis instead of oxidative phosphorylation even in the presence of oxygen, a phenomenon known as the Warburg effect [2], which is also typical for many nontransformed cells during rapid proliferation. The main function of glycolysis is to provide anabolic substrates, not the ATPs, in the rapidly proliferating cells $[3,4]$. Although energy production in glycolysis is less efficient than oxidative phosphorylation, the enhanced glycolysis provides essential metabolic intermediates important for cell growth and survival. 
In the three rate-limiting enzymes (hexokinase, PFK-1, and pyruvate kinase) involved in glycolysis [5], PFK-1 catalyzes the conversion of fructose 6-phosphate to fructose-1,6-bisphosphate (F1,6BP) and serves as a gatekeeper in metabolic degradation of glucose. PFK-1 is controlled by the downstream metabolites, mainly by its allosteric activator, fructose-2,6-bisphosphate (F2,6BP), which is synthesized and degraded under the regulation of a bifunctional enzyme, 6-phosphofructo-2-kinase/fructose2,6-bisphosphatase (PFK-2/FBPase) [6]. Several PFK-2/ FBPase-2 isoenzymes encoded by four different genes, PFKFB1 to PFKFB 4, have been characterized in mammals [7], and showed distinct regulatory and kinetic properties (kinase and phosphatase activities). PFKFB3 is known to have the highest ratio $(>700)$ of kinase/phosphatase activity to maintain the elevated level of F2,6BP, thereby sustaining a high rate of glycolysis $[1,8]$. It is highly expressed in tumor, endothelial, and the activated immune cells, and plays an essential role in regulating metabolism, angiogenesis, and inflammation [1,9]. Meanwhile, it can be induced by progesterone, inflammatory stimuli, and hypoxia. Unlike other PFK-2/FBPase isoforms, PFKFB3 can localize in both cytoplasm (the site of glycolysis) and nucleus, and the nuclear PFKFB3 increases cell proliferation and the expression of several key cell cycle proteins, but decreases the expression of cell cycle inhibitors [10]. It has been reported that the inhibition of PFKFB3 promoted autophagy in HCT116 cells [11], while knockdown of PFKFB3 restrained the activation of autophagy in rheumatoid arthritis T cells [12]. Thus, the role of PFKFB3 in regulating autophagy remains unclear and controversial.

Macroautophagy (hereafter called autophagy) is an evolutionarily conserved catabolic, intracellular membrane trafficking process involved in the delivery of cytoplasmic contents and organelles to lysosomes for degradation [13]. It is induced under various conditions, such as amino acids starvation and energy stress [14]. In eukaryotic cells, the mammalian target of rapamycin (mTOR) and the AMP-activated protein kinase (AMPK) signaling pathways are essential regulators of autophagy $[15,16]$. In addition, mTOR complex-1 (mTORC1), activated by amino acids and blocked by rapamycin (Rapa) [17], is one of the key sensors for amino acids in mammal cells, whereas AMPK, a member of the serine/threonine protein kinases, is a highly conserved sensor for the intracellular adenosine nucleotides and plays a key role in regulating energy homeostasis [18]. The phosphorylation of a conserved threonine residue (Thr172) in the catalytic $\alpha$-subunit is thought to be prerequisite for the activity of AMPK [19]. Several AMPK upstream activating kinases have been identified, such as LKB1 (liver kinase B1), CaMKK2 (Calcium/Calmodulin-dependent Protein Kinase Kinase 2), and TAK1 (transforming growth factor $\beta$-activated kinase-1). It is well known that various cellular stresses can activate AMPK. Adenosine monophosphate (AMP) and diphosphate (ADP) inhibit Thr172 dephosphorylation and promote the activity of AMPK, whereas adenosine triphosphate (ATP) shows the opposite effect [20]. In addition to physiological AMP/ADP elevation resulted from the stresses, such as low nutrients or prolonged exercise, pharmacological agents including 5-aminoimidazole-4-carboxamide1$\beta$-d-ribofuranoside (AICAR) and metformin, can also activate AMPK [21]. And compound C (CC) is a widely used ATP-competitive inhibitor of AMPK [21]. Regarding autophagic regulation, AMPK can activate autophagy by deactivating its negative regulator mTORC1 [22]. Recently, AMPK was found to mediate autophagy by direct phosphorylation of its initiator Ulk1, a serine/ threonine kinase and the mammalian functional homolog of the yeast ATG1 $[15,23]$. Thus, AMPK could activate autophagy via a "double insurance" mechanism. However, AMPK was also reported to inhibit autophagy in isolated rat hepatocytes [24]. Therefore, AMPK plays bidirectional roles in autophagy regulation.

In the current work, we have proved that inhibition of PFKFB3 not only inhibited the basal autophagy, but also blunted the rasfonin- or $\mathrm{H}_{2} \mathrm{O}_{2}$-upregulated autophagic flux. Furthermore, PFKFB3 showed nuclear localizing property, and its regulatory roles in autophagy were subcellular localization-dependent and associated with the AMPK signaling pathway.

\section{RESULTS}

\section{PFK-15 inhibits the autophagic processes}

To clarify the function of PFKFB3 in autophagy regulation, PFK-15, a small molecule antagonist of PFKFB3 [25], was used and the aroused autophagy was monitored. Since renal cell carcinoma (RCC) is a model to study the role of an oncologic-metabolic shift (commonly referred as the "Warburg effect") leading to malignancy [26], renal cancer cell line ACHN was selected for this study. Considering the fact that treatment of ACHN cells with $6 \mu \mathrm{M}$ PFK-15 significantly decreased the level of secreted lactate (final product of glycolysis) at the time of detection (Figure 1A), a concentration of $6 \mu \mathrm{M}$ was also used for PFK-15 in the following experiments.

Under transmission electron microscopy (TEM) [27], formation of autophagosomes was reduced and the area ratios of autophagosomes to whole cells were significantly decreased in the PFK-15-treated cells (Figure 1B). In immunofluorescence assay, we found that PFK-15 treatment decreased the punctate staining of LC3, the mammalian homolog of yeast Atg8 (Figure 1C). While immunoblotting results revealed that PFK-15 decreased the level of LC3-II but increased the amount of autophagy substrate p62 (Figure 1D). Chloroquine (CQ), a known inhibitor of autolysosome degradation widely used in monitoring autophagic flux [28], failed to 
accumulate LC3-II and block p62 degradation in the PFK15-treated cells (Figure 1D). In HeLa cells, PFK-15 also completely inhibited autophagy as evidenced by LC3-II accumulation and p62 degradation in the presence of CQ (Supplementary Figure 1A). Furthermore, bafilomycin A1 (Baf-A1), which blocks the fusion of autophagosomes and lysosome [28], showed similar effect to CQ on the PFK-15-regulated autophagy in both HeLa and ACHN cells (Supplementary Figure 1B and 1C). These results indicated that PFK-15 inhibits the basal autophagy.

\section{PFK-15 attenuates autophagy upon stimulation with either rasfonin or $\mathrm{H}_{2} \mathrm{O}_{2}$}

Rasfonin, a natural product originally isolated from the fungus Talaromyces sp. 3656-A1 and named for its activity against the small G-protein Ras, has been demonstrated to promote the autophagic process in our previous study [29]. Here it was found to cause obvious accumulation of membrane vacuoles in a timedependent manner (Supplementary Figure 2A) and to affect the ratios of LC3-II/actin in a duration-dependent manner, but to promote p62 degradation at all time points by immunoblotting (Supplementary Figure 2B). While rasfonin increased the ratios of LC3-II/actin at both the 1 and $12 \mathrm{~h}$ time points, it decreased the level of LC3-II at either 2 or $4 \mathrm{~h}$ treatment (Supplementary Figure 2C and 2D). However, CQ blocked the rasfonin-induced downregulation of LC3-II or p62 at all the time points tested (Supplementary Figure 2C and 2D), suggesting an enhanced autophagic flux. The aforementioned results showed that rasfonin promoted lysosomal turnover of endogenous LC3, an autophagy marker [30], and could be used as an autophagy inducer. Treatment of ACHN cells with a combination of rasfonin and PFK-15 accumulated less LC3-II in the presence of CQ (Figure 2A; folds: lane 5 vs 3 ), and failed to degrade p62 compared to that with rasfonin alone (Figure 2A; lane 4 vs 2). It is generally accepted that autophagy regulation is not simply in a "either promotion or inhibition" pattern, inhibition to certain extent is usually observed [31]. In the PFK15/rasfonin treated cells, CQ still accumulated LC3II, suggesting occurrence of an incompletely blocked autophagic process. In fact, CQ failed to increase the level of p62 in the PFK-15/rasfonin treated cells (Figure 2A). Here, "changed folds" was used to indicate the
A

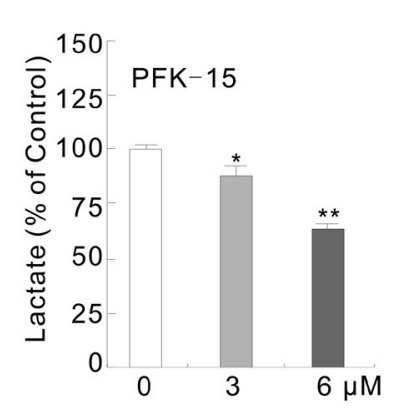

C

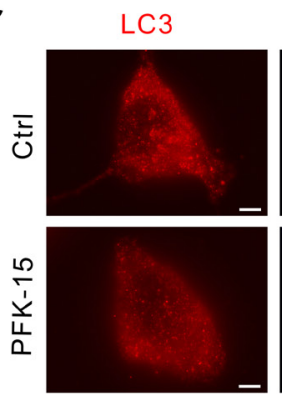

B
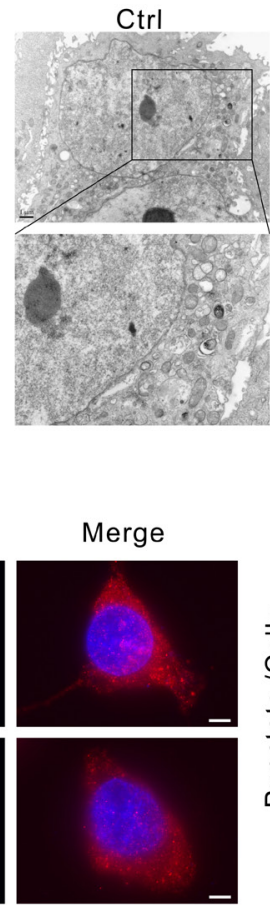

PFK-15
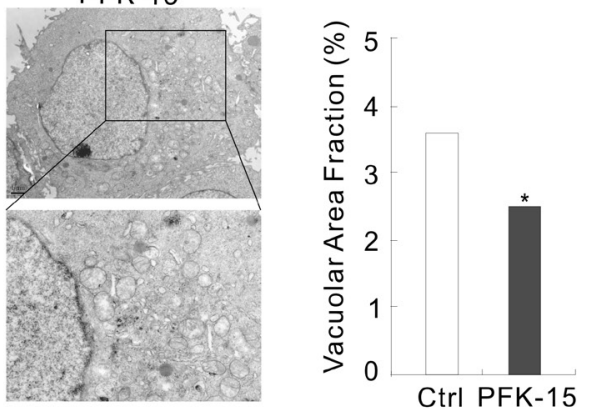

D

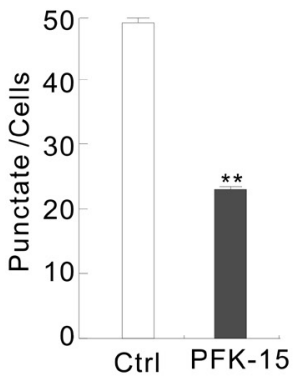

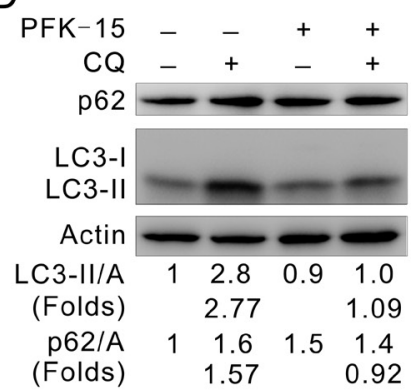

Figure 1: PFKFB3 inhibitor PFK-15 reduces autophagy in ACHN cells. (A) ACHN cells were treated with PFK-15 (0-6 $\mu$ M) for $12 \mathrm{~h}$, and the secreted lactate was analyzed. (B) Electron microscopy was performed following treatment with PFK-15 (6 $\mu \mathrm{M}$ unless otherwise indicated) for $2 \mathrm{~h}$. Morphometric analysis of the area fractions between autophagosomes and cytoplasm were calculated using ImageJ software. The data of area ratios were non-normally distributed and presented as the mean of at least 20 cells counted for each group. (C) Immunofluorescence using the LC3 antibody was performed following treatment with PFK-15 for $2 \mathrm{~h}$. Numbers of the punctate LC3 in each cell were counted, and at least 30 cells were included for each group. Bar $=10 \mu \mathrm{m}$. (D) Following treatment with PFK-15 in the presence or absence of $10 \mu \mathrm{M} \mathrm{CQ}$ for $2 \mathrm{~h}$, cell lysates were prepared and analyzed by immunoblotting using the indicated antibodies. For histogram results, the data were presented as mean \pm S.D. and analyzed by T-test. $* \mathrm{P}<0.05$ vs control; **P $<0.01$ vs control. 
magnitude in changes for the levels of LC3-II/Actin and p62/Actin compared to that without CQ, which represent the intensity of autophagic flux. Treatment of HeLa cells with PFK-15 completely blocked the rasfonin-induced autophagy, as evidenced by accumulation of LC3-II and degradation of p62 in the presence of CQ (Supplementary Figure 3A; folds: lane 5 vs 3).

Reactive oxygen species (ROS), highly reactive oxygen free radical or non-radical molecules produced by multiple mechanisms [32], has been demonstrated to promote the starvation-induced autophagy, antibacterial autophagy, and autophagic cell death [33]. As a donor of ROS, $\mathrm{H}_{2} \mathrm{O}_{2}$ was widely used as an autophagy inducer [34]. Here, we observed that $\mathrm{H}_{2} \mathrm{O}_{2}$ alone induced autophagic flux, but PFK-15 completely inhibited this process (Figure 2B; folds: lane 5 vs 3 ). However, PFK15 failed to attenuate the Rapa-induced autophagy as CQ normally blocked the autophagic flux in the PFK-15/ Rapa-treated cells (Figure 2C; folds: lane 5 vs 3 ). These results indicated that that PFK-15 regulates autophagy in a stimulus type-dependent manner.

\section{Deprivation of PFKFB3 attenuates the rasfonin- and $\mathrm{H}_{2} \mathrm{O}_{2}$-induced autophagy}

To verify the results obtained from PFK-15 treatments, PFKFB3 in ACHN cells was genetically deprived using target siRNA. Deprivation of PFKFB3 decreased the basal level of LC3-II, and treatment with rasfonin accumulated less LC3-II in the presence of CQ (folds: lane 6 vs 3 ) and failed to degrade p62 (lane 5 vs 2) in the PFKFB3-depleted cells (Figure 2D). Similar results were also obtained in HeLa cells (Supplementary Figure $3 \mathrm{~B})$. In the $\mathrm{H}_{2} \mathrm{O}_{2}$-treated cells, loss of PFKFB3 decreased the autophagic flux (Supplementary Figure 3C; folds: lane 3 vs 6), while silencing of PFKFB3 significantly decreased secreted lactate in ACHN and HeLa cells (Figure 2E and Supplementary Figure 3D). However, deprivation
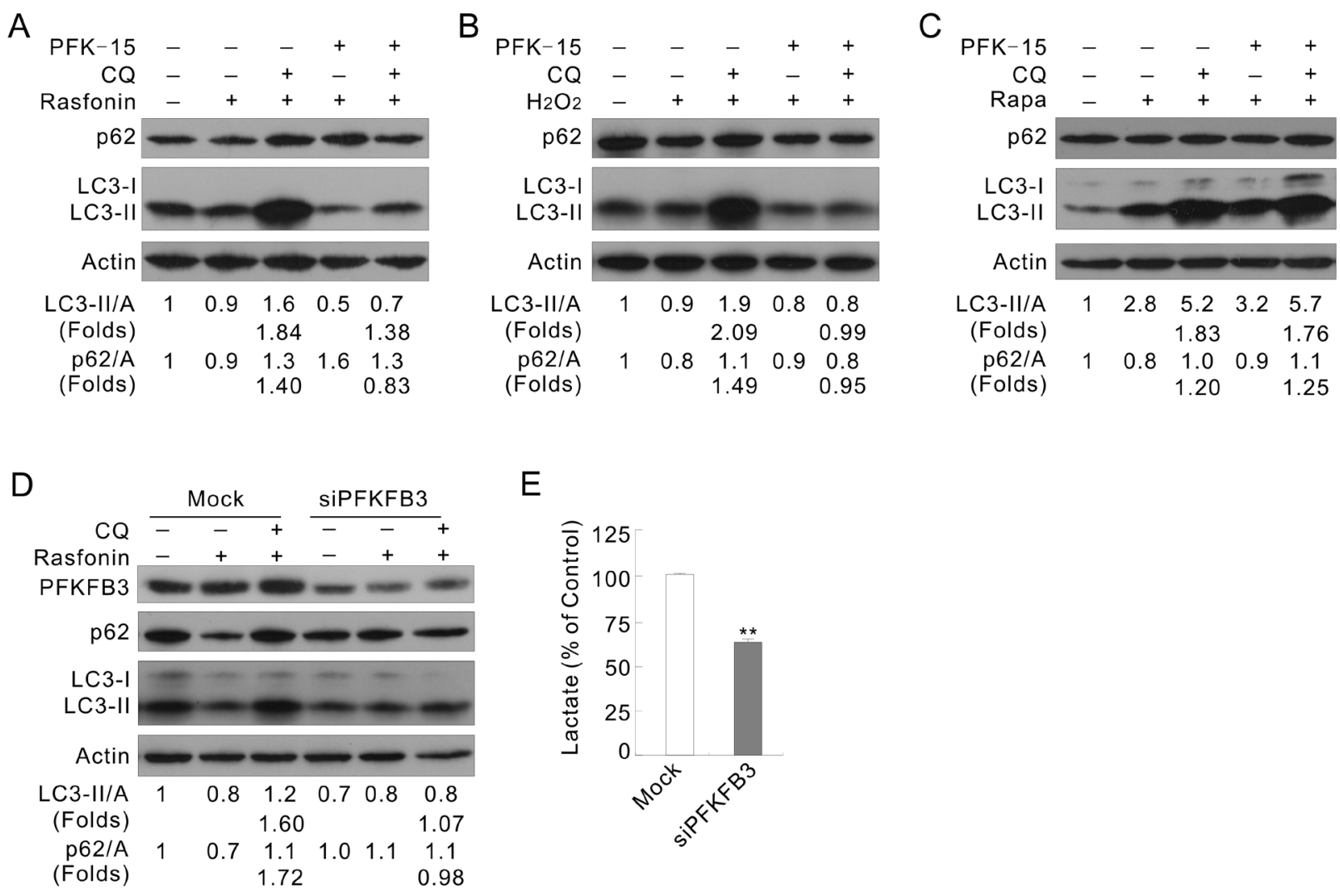

Figure 2: Inhibition of PFKFB3 attenuates the rasfonin-induced autophagy. (A) ACHN cells were treated with $6 \mu \mathrm{M}$ rasfonin or a combination with PFK-15 in the presence or absence of $10 \mu \mathrm{M}$ CQ for $2 \mathrm{~h}$. Cell lysates were prepared and analyzed by immunoblotting. (B and C) ACHN cells were treated with $\mathrm{H}_{2} \mathrm{O}_{2}$, or $0.1 \mu \mathrm{M}$ Rapa or a combination with PFK-15 in the presence or absence of CQ for $2 \mathrm{~h}$. (D and E) ACHN cells were transfected with PFKFB3 or the Mock control siRNAs for $48 \mathrm{~h}$. The lysates were analyzed by immunoblotting following treatment with $6 \mu \mathrm{M}$ rasfonin for $2 \mathrm{~h}$ in the presence or absence of $10 \mu \mathrm{M}$ CQ (D). Suspension was collected before drug treatment and lactate assay was performed (E), and double asterisk means $\mathrm{p}<0.01$. 
of PFKFB3 in ACHN cells failed to attenuate the Rapainduced autophagy (Supplementary Figure 3E).

\section{The K472/473A mutant fails to localize in nucleus}

Since PFKFB3 has been reported to localize in the nuclei of HeLa cells [10], subcellular localization of endogenous PFKFB3 was examined in HeLa and ACHN cells. Distribution of PFKFB3 in HeLa cells was investigated by immunoelectron microscopy, and dots of immunogold were observed in both nuclei and cytoplasm (Figure 3A). In immunofluorescence assay, PFKFB3 mainly localized in the nuclei of ACHN and HeLa cells as observed by either fluorescence microscopy or confocal microscopy (Figure 3B and Supplementary Figure 4A). To further determine its localization, the protein expression in total homogenate $(\mathrm{TH})$ and the nuclear fractions $(\mathrm{Nu})$ extracted from ACHN cells were examined. As expected, the expression of mainly PFKFB3 was detected in the nuclear fractions (Supplementary Figure 4B), using actin and PARP-1 (poly ADP-ribose polymerase; an enzyme
A

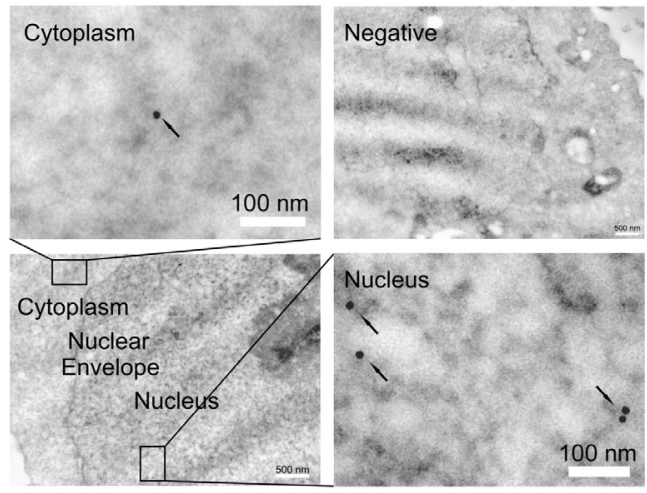

B
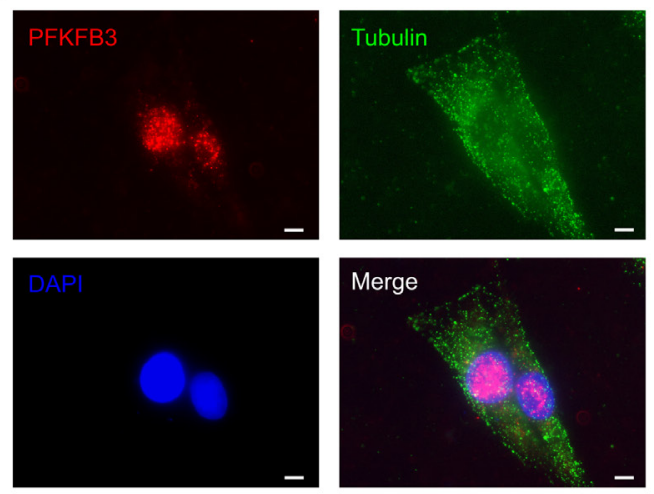

C

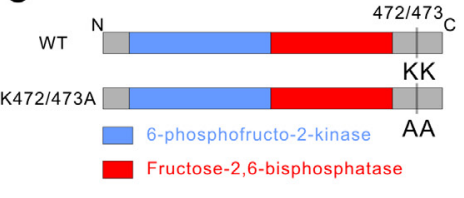

$\mathrm{D}$

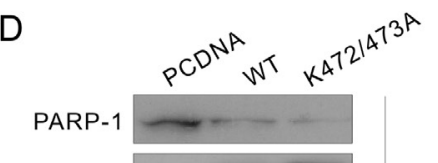

PFKFB3

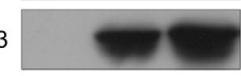

Histone $\mathrm { H } 3 \longdiv { \mathrm { TH } }$
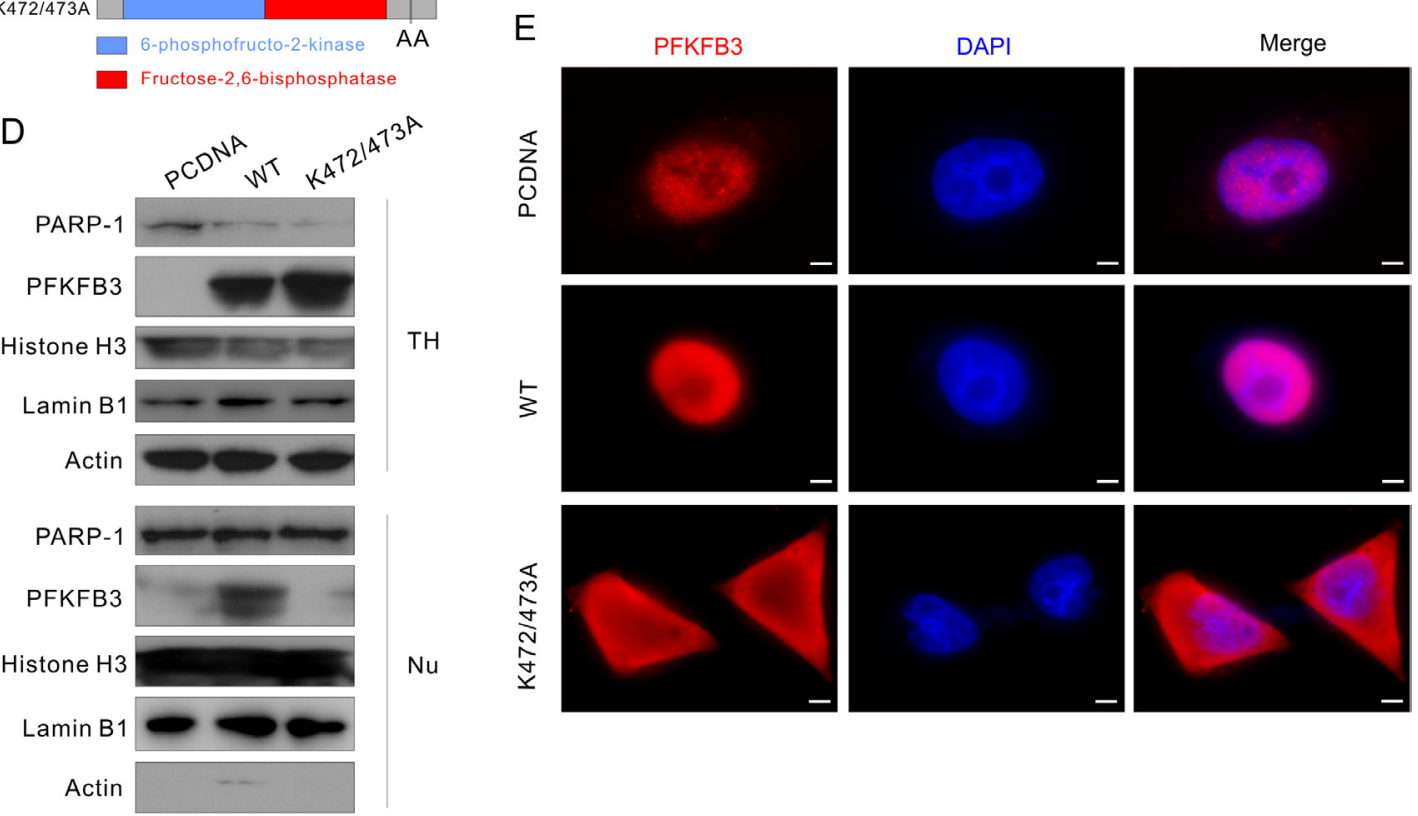

Figure 3: K472/473A mutation changes the nuclear localization of PFKFB3. (A) HeLa cells were analyzed by immunoelectron microscopy using anti-PFKFB3 antibody. Images are representative of at least 20 cells. Arrowheads, PFKFB3 signals (gold particles). The negative control was prepared without addition of specific antibody. (B) Immunofluorescence was performed for ACHN cells using the antibodies of PFKFB3 and Tubulin, and the nuclei were stained by DAPI. Bar $=20 \mu \mathrm{m}$. (C) Schematic diagram of WT PFKFB3 (top) and K472/473A mutated PFKFB3 (bottom). (D and E) After transfection with the PCDNA, WT or K472/473A plasmids, TH and Nu subcellular fractions were extracted from ACHN cells and analyzed by immunoblotting with the antibodies indicated (D); cells were stained using the PFKFB3 antibodies and the nuclei were stained by DAPI (E). Bar $=10 \mu \mathrm{m}$. Images were representative of at least 20 cells. 
involved in DNA repair) as the markers for $\mathrm{TH}$ and $\mathrm{Nu}$ [35], respectively. Meanwhile, either Lamin B1 or histone H3, two often used nuclear markers [36, 37], was also detected (Supplementary Figure 4B).

The structural organization of PFKFB3 is similar to other isoenzymes, with the kinase and bisphosphatase domains located in the center flanked by regulatory regions (Figure 3C). Since the K472 and K473 lysine residues at the carboxyl terminal are essential for nuclear targeting [10], they were replaced by alanine residues using sitedirected mutagenesis (Figure 3C). The expression and distribution patterns of the K472/473A mutated PFKFB3 were confirmed by immunoblotting after subcellular fractionation (Figure 3D). Except for the difference in fluorescence intensity, distribution of PFKFB3 remained nearly unchanged, localizing in the nuclei of either the PCDNA- or WT-transfected cells, whereas the K472/473A mutated PFKFB3 mainly localized in cytoplasm (Figure 3E; exposure time: $800 \mathrm{~ms}$ for PCDNA, $100 \mathrm{~ms}$ for WT and K472/473A). Similar results were also obtained in HeLa cells (Supplementary Figure 4C). Taken together, the K472/473A mutation of PFKFB3 altered its nuclear localization.

\section{Overexpression of the K472/473A mutated PFKFB3 partially inhibits autophagy}

To investigate whether PFKFB3 spatially regulate autophagy, ACHN or HeLa cells were transfected with the plasmids carrying either the WT or K472/473A mutated PFKFB3. Overexpression of the WT, not the K472/473A mutated PFKFB3, enhanced the autophagy upon rasfonin stimulation in ACHN cells by evaluating LC3-II accumulation and p62 degradation in the absence or presence of $\mathrm{CQ}$ compared to the PCDNA-control cells (Figure 4A and 4B; folds: lane 6 vs 3). The basal level of LC3-II was increased in WT PFKFB3-, but not K472/473A mutated PFKFB3-transfected cells. Similarly, WT PFKFB3 promoted the rasfonin-induced autophagic flux, and K472/473A mutated one partially attenuated this process in HeLa cells (Supplementary Figure 5A; lane 3 vs 6 vs 9). In addition, overexpression of the WT PFKFB3 promoted the $\mathrm{H}_{2} \mathrm{O}_{2}$-dependent autophagy (Supplementary Figure 5B; lane 6 vs 3), whereas the K472/473A mutant partially inhibited the induced autophagy (Supplementary Figure 5B; lane 9 vs 3). Here, the induced rather than the basal autophagy was the focus of our study, and inconsistency between the LC3-II levels of the Mock- and PCDNA-control cells was indeed noticed upon individual treatment with rasfonin or $\mathrm{H}_{2} \mathrm{O}_{2}$, which could be resulted from the alteration in cell condition after transfection [28, 30]. Therefore, the autophagic flux instead of the level of LC3-II was analyzed in all the experiments. The punctate staining of LC3 was obviously increased in the WT PFKFB3, but not the K472/473A-transfected cells without any treatment in immunofluorescence assay (Figure 4C).
Interestingly, both the WT and K472/473A mutated PFKFB3 promoted lactate secretion, and overexpression of the latter generated more lactate (Figure 4D), which is in agreement with the report that $N$-methyl-d-aspartate subtype of glutamate receptors (NMDAR)-induced cytosol localized PFKFB3 increased the rate of glycolysis [38]. These results indicated that nuclear localization of PFKFB3 plays a critical role in regulation of autophagy, but whether lactate is involved in the process remained uncovered.

\section{AMPK is involved in the PFKFB3-regulated autophagy}

AMPK, a sensor for intracellular adenosine nucleotides, responds to the changes in energy status and coordinates cell growth, autophagy, and metabolism [18]. Since it generally phosphorylates PFKFB3 at Ser461, its role in the PFKFB3-mediated autophagy was explored. Treatment with PFK-15 alone decreased the phosphorylation of AMPK $\alpha$ and ACC (acetyl-CoA carboxylase) at Ser79, a known substrate of AMPK [39], suggesting that PFK-15 inhibited the activity of AMPK in both ACHN and HeLa cells (Figure 5A and Supplementary Figure 6A). Moreover, PFK-15 reduced the phosphorylation of both AMPK $\alpha$ and ACC upregulated by $\mathrm{H}_{2} \mathrm{O}_{2}$ stimulation (Supplementary Figure 6B). However, different from treatment with $\mathrm{H}_{2} \mathrm{O}_{2}$, rasfonin treatment induced autophagy concurring with inhibition of both the phosphorylation and activity of AMPK $\alpha$ (Figure $5 \mathrm{~B})$. In addition, deprivation of PFKFB3 reduced the basal and the induced phosphorylation of ACC, suggesting that loss of PFKFB3 attenuated the activity of AMPK (Figure 5C and Supplementary Figure 6C). Although rasfonin and $\mathrm{H}_{2} \mathrm{O}_{2}$ have been demonstrated to oppositely regulate the activity of $\mathrm{AMPK}$, deprivation of PFKFB3 decreased the phosphorylation of $\mathrm{AMPK} \alpha$ in response to stimulation with either rasfonin or $\mathrm{H}_{2} \mathrm{O}_{2}$ (Figure $5 \mathrm{C}$ and Supplementary Figure 6C), and loss of PFKFB3 obviously suppressed the $\mathrm{H}_{2} \mathrm{O}_{2}$-induced phosphorylation of ACC (Supplementary Figure 6C). Therefore, we speculated that PFKFB3 might function upstream of AMPK. In contrast to the K472/473A-transfected cells, overexpression of the WT PFKFB3 increased the $\mathrm{H}_{2} \mathrm{O}_{2}$-induced phosphorylation of ACC and AMPK $\alpha$, suggested the enhanced AMPK activity (Supplementary Figure 6D and 6E). However, the K472/473A mutated PFKFB3 decreased the phosphorylation of AMPK $\alpha$ in untreated, and rasfonin- and $\mathrm{H}_{2} \mathrm{O}_{2}$-treated ACHN cells (Figure 5D and 5E; Supplementary Figure 6D and 6E). Considering that WT PFKFB3 differently regulated the phosphorylation of AMPK $\alpha$ in the rasfonin- and $\mathrm{H}_{2} \mathrm{O}_{2}$ treated cells, but promoted the induced autophagy, PFKFB3 regulates autophagy through multiple pathways including AMPK, and AMPK may play a dual role in regulation of autophagy in the same cells. 


\section{Bidirectional roles of AMPK in regulating autophagy}

Despite the fact that rasfonin decreased the activity of AMPK, it also blunted the $\mathrm{H}_{2} \mathrm{O}_{2}$-promoted phosphorylation of AMPK $\alpha / \mathrm{ACC}$ levels, and inhibited the $\mathrm{H}_{2} \mathrm{O}_{2}$-dependent autophagic flux (Figure 6A and $6 \mathrm{~B})$, suggesting involvement of AMPK in the process. To prove the hypothesis, a widely used inhibitor of AMPK, CC was used in the experiments [21]. Similar to previous study, in which CC inhibited the activity of AMPK independent of phosphorylation, but decreased the activity of its downstream molecule [40], CC was found to increase the basal phosphorylation of AMPK $\alpha$ (Figure 6C). Nevertheless, decrease in both the basal and the $\mathrm{H}_{2} \mathrm{O}_{2}$-induced phosphorylation of ACC suggested that $\mathrm{CC}$ definitely inhibited the activity of AMPK (Figure

A

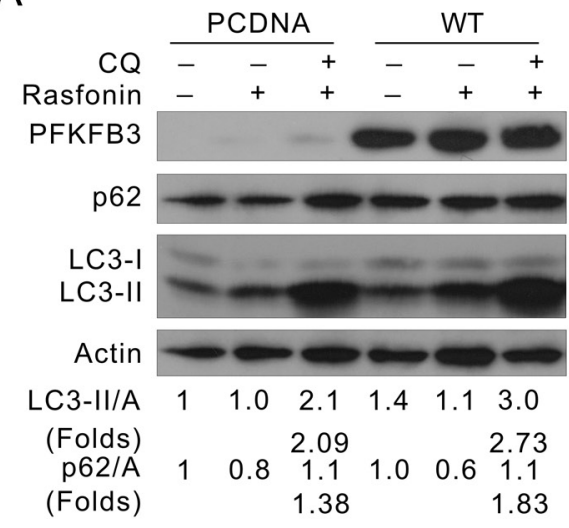

C
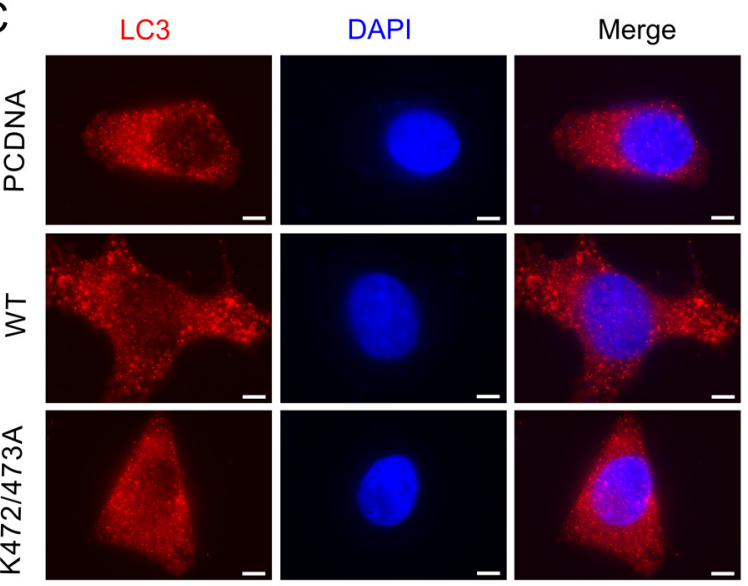

6C). Consistent with that reported previously [41], treatment with $\mathrm{CC}$ alone increased the autophagic flux (Supplementary Figure 7A). However, the $\mathrm{H}_{2} \mathrm{O}_{2}$-induced autophagic flux was reduced by $\mathrm{CC}$ since the fold changes were remarkably decreased in the $\mathrm{H}_{2} \mathrm{O}_{2} / \mathrm{CC}$-treated ACHN cells (Figure 6D). On the contrary, $\mathrm{CC}$ further enhanced the autophagic flux induced by rasfonin (Supplementary Figure 7B; folds: lane 5 vs 3). Different from CC treatment, the AMPK agonist AICAR further increased the $\mathrm{H}_{2} \mathrm{O}_{2}$-induced phosphorylation of AMPK $\alpha$ and ACC (Supplementary Figure 7C), and promoted the basal and $\mathrm{H}_{2} \mathrm{O}_{2}$-dependent autophagy (Supplementary Figure 7D; folds: lane 7 vs 3). These results indicated that AMPK is indeed required to activate the autophagic process in response to $\mathrm{H}_{2} \mathrm{O}_{2}$ challenge, but negatively regulates the rasfonin-induced autophagy. Thus, it played a dual role in regulating autophagy depending on the type of stimulus.

B
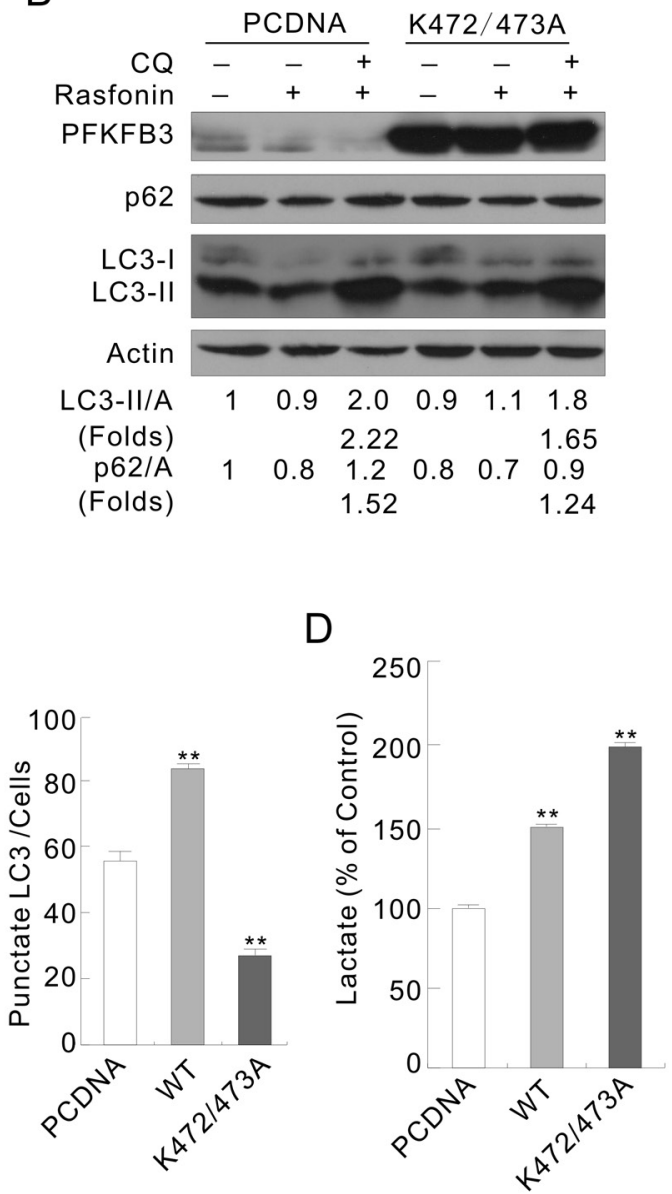

Figure 4: The WT and K472/473A mutated PFKFB3s play different roles in regulating autophagy. ACHN Cells were transfected with the indicated plasmids for $36 \mathrm{~h}$. (A and B) Following treatment with $6 \mu \mathrm{M}$ rasfonin in the presence or absence of $10 \mu \mathrm{M}$ CQ for $2 \mathrm{~h}$, cell lysates were analyzed by immunoblotting with the antibodies indicated. (C) LC3 antibody was used to label the endogenous LC3, and DAPI was used to stain the nuclei. Pictures were taken by fluorescence microscopy. Numbers of the punctate LC3 in each cell were counted, and at least 30 cells were included for each group. Bar $=10 \mu \mathrm{m}$. (D) Suspension was collected before the treatment and lactate assay was performed. Double asterisk means $\mathrm{p}<0.01$. 


\section{Deprivation of AMPK $\alpha$ differently regulates the $\mathrm{H}_{2} \mathrm{O}_{2}-$ and rasfonin-induced autophagy}

To further investigate the role of AMPK in the PFKFB3-mediated autophagy, AMPK $\alpha 1 / 2$ was knocked down in ACHN cells by target siRNA. Interestingly, deprivation of AMPKa1/2 inhibited the induced autophagy (Figure 7A; lane 8 vs 3 ) concurring with the reduced phosphorylation of ACC in response to $\mathrm{H}_{2} \mathrm{O}_{2}$ challenge (Figure 7B). The basal level of LC3-II was also slightly decreased in the AMPK $\alpha 1 / 2$-depleted cells (Figure 7A; lane 6 vs 1). Notably, PFK-15 suppressed the $\mathrm{H}_{2} \mathrm{O}_{2}$-induced autophagy in the Mock-control cells (Figure $7 \mathrm{~A}$; lane 5 vs 3 ), and displayed less inhibitory effect on the $\mathrm{H}_{2} \mathrm{O}_{2}$-induced autophagy in the AMPK $\alpha 1 / 2$-depleted cells (Figure 7A; lane 10 vs 8 ). Since PFK-15 still showed inhibitory effect on the $\mathrm{H}_{2} \mathrm{O}_{2}$-induced autophagy in the AMPK $\alpha 1 / 2$-depleted cells, we speculated that an effector other than AMPK $\alpha$ might function downstream of PFKFB3 to regulate the induced autophagic process. While PFK-15 inhibited the induced autophagy in the
Mock-control or AMPK $\alpha 1 / 2$-depleted cells (Figure 7C; lane 5 vs 3 and lane 10 vs 8), deprivation of AMPK $\alpha 1 / 2$ failed to attenuate the rasfonin-induced autophagic flux (Figure 7C and 7D; lane 8 vs 3), which is consistent with the fact that rasfonin induced autophagy accompanied by decreased phosphorylation of AMPK $\alpha$. Thus, we assumed that PFKFB3 and AMPK might function in the same regulating axis to mediate autophagy, and PFKFB3 exerts its regulatory effect at least partially through AMPK under certain circumstances. Taken together, PFKFB3 regulated autophagy depending on its nuclear localization and relating to the AMPK signaling.

\section{DISCUSSION}

A new finding of the present study is that the nuclear localization of PFKFB3 plays an essential role in regulating autophagy. Apparently, PFKFB3 regulates autophagy in a stimulus-dependent manner, as both the $\mathrm{H}_{2} \mathrm{O}_{2}$ - and rasfonin-induced, but not Rapa-induced autophagy, could be suppressed by inhibition of PFKFB3.
A

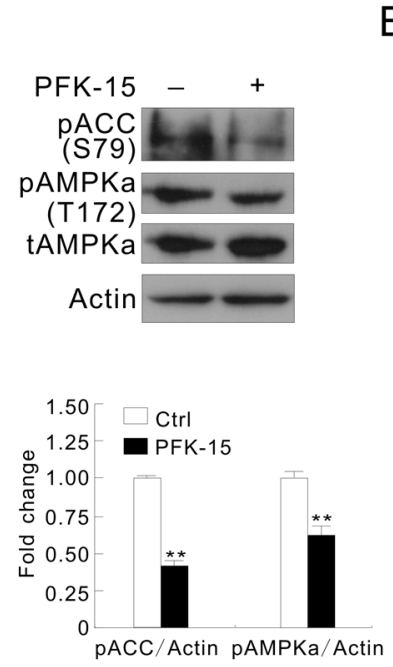

B

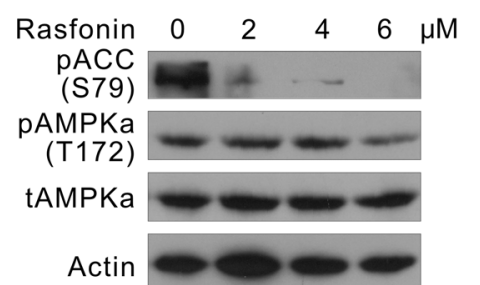

C
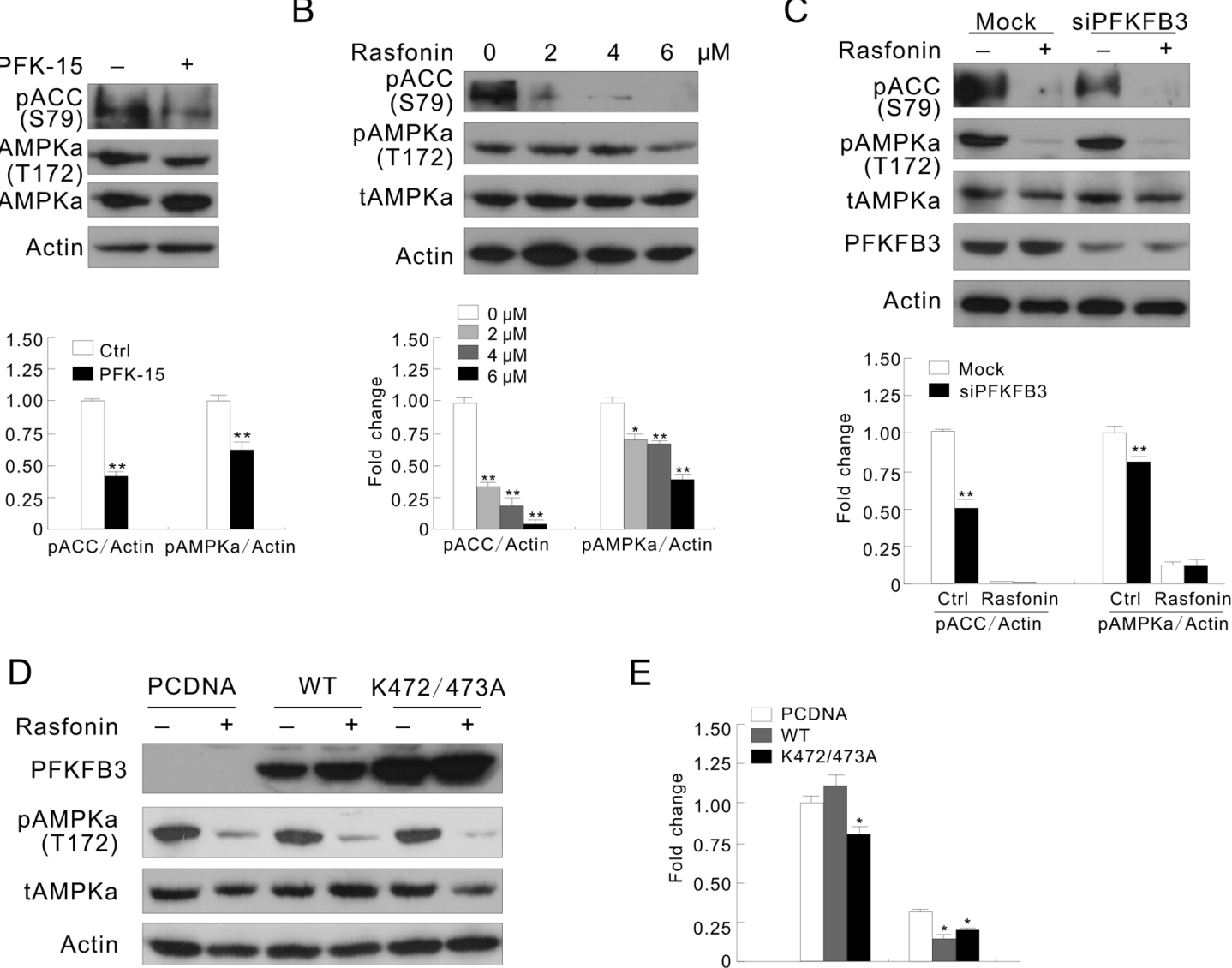

E

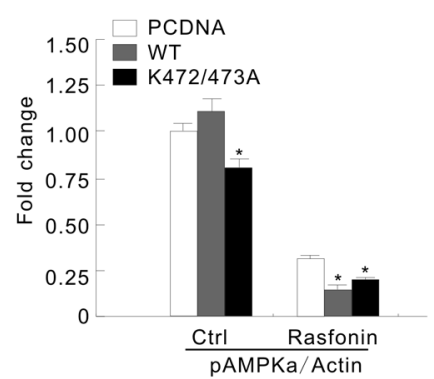

Figure 5: AMPK is involved in the PFKFB3-regulated autophagy process. (A) ACHN cells were treated with PFK-15 for 2 h. (B) ACHN cells were treated with 0-6 $\mathrm{M}$ rasfonin for $2 \mathrm{~h}$. (C) After transfection with PFKFB3 or the Mock control siRNAs for 48 h, ACHN cells were treated with $6 \mu \mathrm{M}$ rasfonin for $2 \mathrm{~h}$. (D and E) Following transfection with the indicated plasmids for 36 h, ACHN cells were treated with $6 \mu \mathrm{M}$ rasfonin for $2 \mathrm{~h}$. Cell lysates were prepared and analyzed by immunoblotting using the indicated antibodies. Quantification of the signals were shown in the bar graphs $(\mathrm{n}=3) .{ }^{*} \mathrm{P}<0.05$ vs control, $* * \mathrm{P}<0.01$ vs. control. 
The K472/473A mutated PFKFB3, which lost nuclear localizing property, inhibited the autophagic process associated with inhibition of the AMPK signaling. While $\mathrm{H}_{2} \mathrm{O}_{2}$ stimulated autophagy with upregulation of the activity of AMPK, either PFK-15 or rasfonin inhibited the $\mathrm{H}_{2} \mathrm{O}_{2}$-stimulated autophagic process concurring with downregulation of the activity of AMPK. Moreover, silencing of AMPK only inhibits the $\mathrm{H}_{2} \mathrm{O}_{2}$-induced, but not the rasfonin-induced autophagy.

In addition to its essential role in glycolytic flux induction, the nuclear targeted PFKFB3 has been demonstrated to promote cell proliferation [10], but whether its subcellular location regulates autophagy remains nearly unexplored. In rheumatoid arthritis $\mathrm{T}$ cells, PFKFB3 deficiency restrained activation of the autophagic process, whereas PFKFB3 inhibition promoted autophagy in HCT116 cells $[11,12]$. Since either PFK-15 or depletion of PFKFB3 inhibited the $\mathrm{H}_{2} \mathrm{O}_{2}$ - and rasfonininduced autophagy, but neither suppressed the Rapadependent autophagic flux, we believe that PFKFB3 is likely to regulate autophagy in stimulus type-dependent manner. Importantly, subcellular localization of PFKFB3 has been demonstrated to play a regulatory role in autophagy. Although the K472/473A mutant stimulated more lactate production than the WT PFKFB3, it inhibited the autophagy induced by rasfonin or $\mathrm{H}_{2} \mathrm{O}_{2}$.

As an evolutionarily conserved energy-sensing kinase, AMPK is activated by metabolic stress or ATP consumption in vivo. Thus, it could also be linked to the regulation of autophagy, which is generally induced upon starvation. In addition to upregulation of AMPK by low cellular energy levels, some stimuli can also induce autophagy via activating AMPK under normal energy levels $[42,43]$. It is well established that AMPK played a critical role to regulate autophagy, for example, to activate autophagy through inactivation of mTORC1 or direct phosphorylation of the protein kinase Ulk1 [19, 22]. Although being widely used as an inhibitor of AMPK, CC shows some special properties, such as inhibition of the activity of AMPK without decreasing the phosphorylation of AMPK $\alpha$ [40], and induction of autophagy by blocking the Akt/mTOR pathway [41]. Consistently, we observed that treatment with $\mathrm{CC}$ alone induced autophagy and inhibited the phosphorylation of ACC, but failed to decrease the phosphorylation of AMPK $\alpha$. However, CC blunted the $\mathrm{H}_{2} \mathrm{O}_{2}$-induced autophagy accompanying by
A

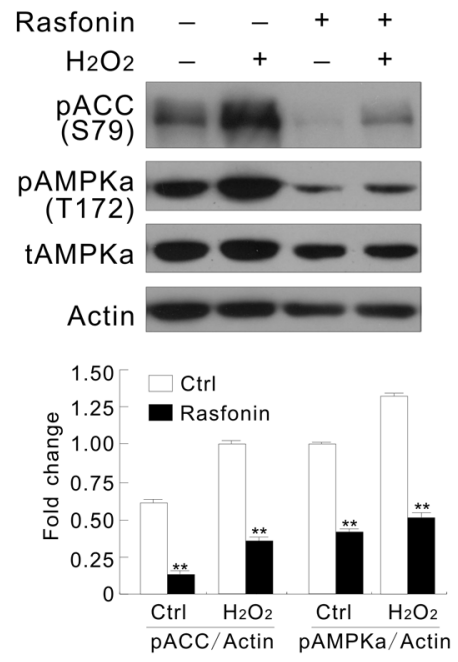

B
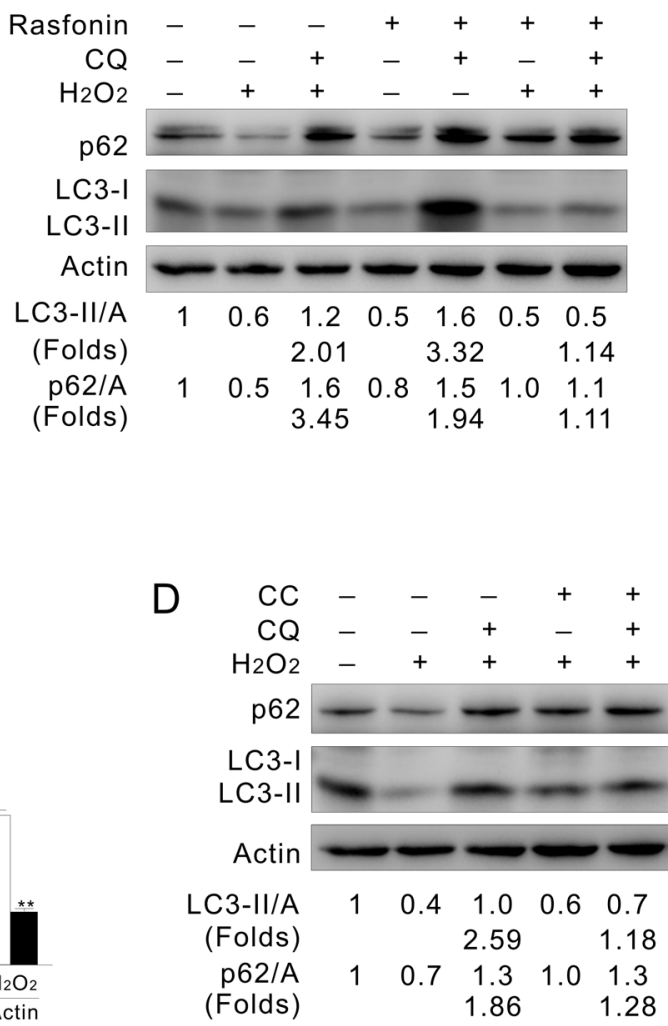

Figure 6: Inhibition of AMPK mimics the effect of inhibition of PFKFB3. (A and B) ACHN cells were treated with $0.1 \mathrm{mM}$ $\mathrm{H}_{2} \mathrm{O}_{2}$ or a combination with $6 \mu \mathrm{M}$ rasfonin in the presence or absence of $10 \mu \mathrm{M}$ CQ for $2 \mathrm{~h}$. (C and D) ACHN cells were treated with 0.1 $\mathrm{mM} \mathrm{H} \mathrm{H}_{2}$ or a combination with $20 \mu \mathrm{M} \mathrm{CC}$ in the presence or absence of $10 \mu \mathrm{M} \mathrm{CQ}$ for $2 \mathrm{~h}$. Cell lysates were prepared and analyzed by immunoblotting using the indicated antibodies. Quantification of the signals were shown in the bar graphs $(\mathrm{n}=3)$. $* * \mathrm{P}<0.01$ vs. control. 
the attenuated phosphorylation of AMPK $\alpha$ and ACC. To avoid the aforementioned observations resulting from the off-target effects of $\mathrm{CC}$, we also used the AMPK agonist AICAR and AMPKa1/2-target siRNAs to verify the results, and all supported that $\mathrm{H}_{2} \mathrm{O}_{2}$ induced autophagy by modulating the AMPK pathway. Interestingly, it was reported that inhibition of AMPK promoted autophagy in rat liver cells [24], here we observed that rasfonin induced autophagy accompanied by downregulation of the activity of AMPK. Rasfonin blunted the $\mathrm{H}_{2} \mathrm{O}_{2}$-upregulated activity of AMPK, and attenuated the autophagy induced by $\mathrm{H}_{2} \mathrm{O}_{2}$. Deprivation of AMPK $\alpha 1 / 2$ only inhibited the $\mathrm{H}_{2} \mathrm{O}_{2}-$, but not the rasfonin-induced autophagy. Thus, AMPK plays bidirectional roles in regulating autophagy, which may associate with the types of stimuli. Since both chemical and genetic inhibition of PFKFB3 dismissed the activity of AMPK, an inner connection between PFKFB3 and AMPK may exist in regulating autophagy.

Prior studies revealed that PFKFB3 was one of the downstream molecules of AMPK, and AMPK activated PFK-2 during ischemia to promote glycolysis [44, 45]. In addition, AMPK mitotic-specifically activates PFKFB3 at translational level, which protect cell survival during mitotic arrest [46]. However, PFKFB3 regulated autophagy by affecting the AMPK signaling, since either the K472/473A mutated PFKFB3 or deprivation of $\mathrm{PFKFB} 3$ reduced the activity of AMPK in response to $\mathrm{H}_{2} \mathrm{O}_{2}$ stimulation. While PFK-15 inhibited the basal and the $\mathrm{H}_{2} \mathrm{O}_{2}$-induced activities of AMPK, deprivation of PFKFB3 slightly increased the AMPK signaling. Expression of the K472/473A mutant reduced the phosphorylation of ACC, whereas the WT PFKFB3 increased the activity of AMPK in response to $\mathrm{H}_{2} \mathrm{O}_{2}$ stimulation. In the AMPK $\alpha 1 / 2$-silenced cells, rasfonin was demonstrated to stimulate autophagic process, which was attenuated by PFK-15, indicating that AMPK functions downstream of PFKFB3 under this circumstance. Thus, we speculated that the relationship between PFKFB3 and AMPK was likely to be cell type- and context-dependent, which was commonly
A

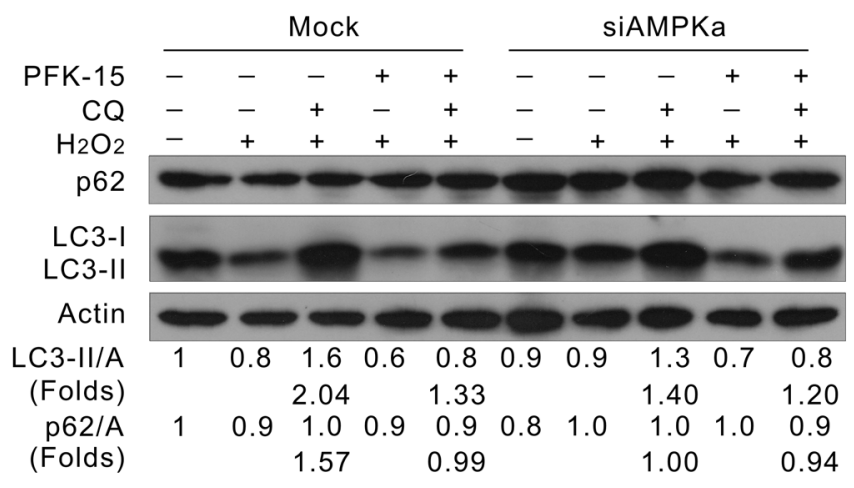

C

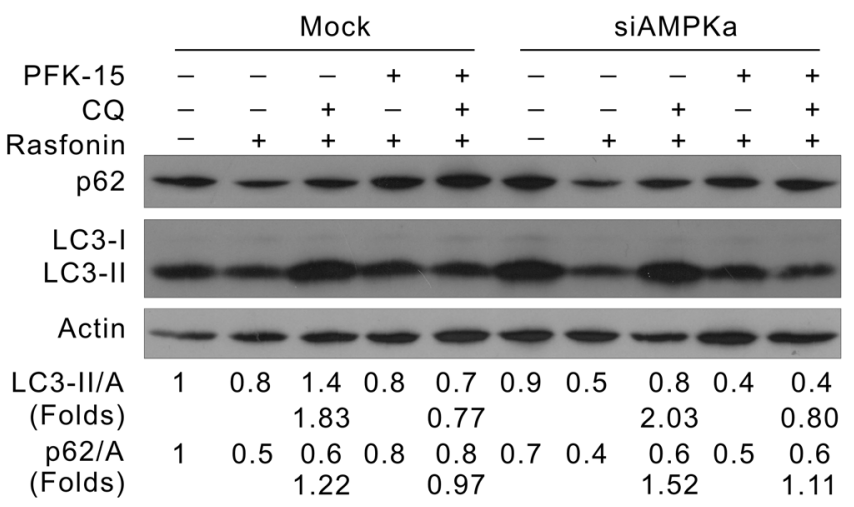

B

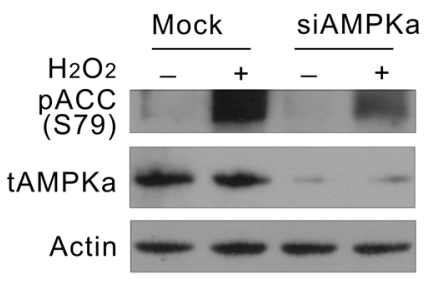

D

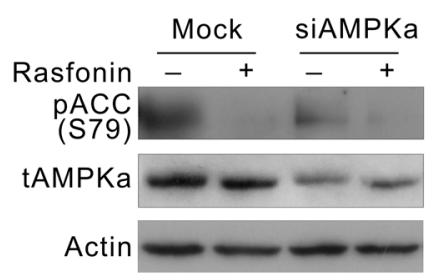

Figure 7: Deprivation of AMPKa suppresses the $\mathrm{H}_{2} \mathrm{O}_{2}-$, but not rasfonin-induced autophagy. ACHN cells were transfected with the AMPK $\alpha 1 / 2$ siRNA for $48 \mathrm{~h}$. (A and B) Cells were treated with $0.1 \mathrm{mM} \mathrm{H}_{2} \mathrm{O}_{2}$, with or without PFK-15 in the presence or absence of $10 \mu \mathrm{M}$ CQ for $2 \mathrm{~h}$. (C and D) Cells were treated with $6 \mu \mathrm{M}$ rasfonin, with or without PFK-15 in the presence or absence of $10 \mu \mathrm{M}$ CQ for $2 \mathrm{~h}$. Cell lysates were prepared and analyzed by immunoblotting using the indicated antibodies. 
found in different signaling pathways, such as crosstalk and compensation between Ras-Erk and PI3K-mTOR signaling [47]. Although it is well established that AMPK activates autophagy via direct phosphorylation of Ulk1 [23], Ulk1 was recently reported to mediate the phosphorylation of AMPK through a negative regulatory feedback loop [48]. Furthermore, AMPK was demonstrated to exert dual regulatory effects on the PI3K pathway [49]. Therefore, it is conceivable that PFKFB3 functions upstream of AMPK under certain circumstance. Considering the inhibitory effect of PFK-15 on the $\mathrm{H}_{2} \mathrm{O}_{2}$ induced autophagy in the AMPK $\alpha 1 / 2$-depleted cells, an effector other than AMPK $\alpha$ might function downstream of PFKFB3 to regulate the induced autophagic process. Although Rapa could activate AMPK [50], we found that inhibition of PFKFB3 showed no effect on the Rapainduced autophagy, which may due to the fact that Rapa affected other signaling molecules, such as Akt and ERK [51].

In summary, the presented data clearly demonstrated that PFKFB3 showed the characteristics of nuclear localization, and the nuclear targeting of PFKFB3 promoted autophagy through the AMPK signaling pathway. In addition, the K472/473A mutation changed the subcellular localizing feature of PFKFB3 and failed to induce autophagy. These results shed light on the glycolytic pathway and autophagy regulation, and provide better understanding for the regulatory mechanism of autophagy.

\section{MATERIALS AND METHODS}

\section{Chemicals and antibodies}

Chloroquine diphosphate salt (CQ, C6628), bafilomycin A1 (Baf-A1, B1793), 1-(4-pyridinyl)-3(2-quinolinyl)-2-propen-1-one (PFK-15, SML1009), Compound C (P5499), AICAR (A9978), 2-deoxyglucose (2-DG, D8375), and polyclonal antibodies against LC3 (L7543) were purchased form Sigma-Aldrich. Antibodies p44/42 MAPK (total-Erk1/2, 9102), PFKFB2 (13029), phospho-AMPK $\alpha$ (Thr172, 2535), total AMPK $\alpha$ (2532), phospho-ACC (Ser79, 3661), beta-tubulin (86298), and PARP-1 (9542) were purchased from Cell Signaling Technology. Antibodies of p62 (sc-28359) was acquired from Santa Cruz Biotechnology. Antibody of PFKFB3 (ab181861) was purchased from Abcam. Antibodies of Histone H3 (17168-1-AP) and Lamin B1 (12987-1AP) were purchased from proteintech. Antibody against actin (TA-09) was obtained from ZhongShanJinQiao Biocompany. Alexa Fluor ${ }^{\circledR} 594$ Goat anti-Rabbit IgG $(\mathrm{H}+\mathrm{L})$ secondary antibody (R37117) and Alexa Fluor $\mathbb{R}$ 488 Goat anti-Mouse IgG $(\mathrm{H}+\mathrm{L})$ secondary antibody (A11001) were purchased from Molecular Probes. Rasfonin is stored in our lab.

\section{Plasmids and siRNAs}

PFKFB3 plasmid was kindly provided by Dr. Yuqing Huo (Augusta University, GA, U.S.A.), and the K472/473A mutated PFKFB3 was constructed in our lab. The siRNA specific for human PFKFB3 (sc-44011), and AMPK $\alpha 1 / 2$ (sc-29673 and sc-38923) were purchased from Santa Cruz Biotechnology, along with the control siRNA (sc-37007).

\section{Cell culture and immunoblotting analysis}

ACHN (human renal cancer) and HeLa (human cervical carcinoma cell line) cells were grown in DMEM media containing 10\% fetal bovine serum (GIBCO) and antibiotics. Cells were grown to $70-80 \%$ confluency before adding the indicated compounds. Cells were treated in completed media containing $10 \%$ serum and collected at the indicted time points. For transfection, cells of $80 \%$ confluency were transfected using Lipofectamine 2000 (Invitrogen) or Attractene (QIAGEN) according to the manufacturer's protocol. After transfection for 24-36 h, cells were split and cultured overnight before subjecting to different treatments, immunoblotting, or analyzed by confocal microscopy.

For siRNA interference, cells of $30 \%$ confluence in their respective media without antibiotics were transfected using DharmaFECT (Dharmacon, T2001 or T2002) according to the manufacturer's instructions. Cells were split and cultured overnight before exposure to indicated treatment after transfection for $48 \mathrm{~h}$. Triton X-100/glycerol buffer (containing $50 \mathrm{mM}$ Tris-HCl, $\mathrm{pH}$ 7.4, 4 mM EDTA, $2 \mathrm{mM}$ EGTA, and $1 \mathrm{mM}$ dithiothreitol, supplemented with $1 \%$ Triton $\mathrm{X}-100,1 \%$ SDS, and protease inhibitors) was used to acquire the whole cell lysates, which were then separated on a SDS-PAGE gel $(13,10$ or $8 \%$ according to the molecular weights for the proteins of interest) and transferred to PVDF membrane. Immunoblotting was performed using appropriate primary antibodies and horseradish peroxidase-conjugated suitable secondary antibodies, followed by detection with enhanced chemiluminescence (Pierce Chemical).

\section{Subcellular fractionation}

Cells were seeded into $100 \mathrm{~mm}$-dishes at 70-80\% confluency. After indicated treatment, cells were gathered, pelleted and washed three times with cold PBS. 20\% cells were resuspended in Triton X-100/glycerol buffer and labeled as total homogenate $(\mathrm{TH})$; the others were resuspended in $400 \mu \mathrm{l}$ homogenization buffer A (10 mM Hepes-KOH [pH 7.9], $10 \mathrm{mM} \mathrm{KCl,} 1.5 \mathrm{mM} \mathrm{MgCl}, 0.5$ $\mathrm{mM}$ PMSF and $0.5 \mathrm{mM}$ dithiothreitol) contained $0.5 \% \mathrm{NP}-$ 40 , and then the homogenate was centrifuged at 3,000 rpm at $4^{\circ} \mathrm{C}$ for $5 \mathrm{~min}$ after static on ice for $15 \mathrm{~min}$. Following wash twice with buffer A without NP-40, the pellet was resuspended in $60 \mathrm{ul}$ buffer $\mathrm{C}(20 \mathrm{mM}$ Hepes-KOH $[\mathrm{pH}$ 
7.9], $600 \mathrm{mM} \mathrm{KCl}, 1.5 \mathrm{mM} \mathrm{MgCl}_{2}, 0.2 \mathrm{mM}$ EDTA and $25 \%$ glycerol). After rotating on ice for $15 \mathrm{~min}$, the homogenate was centrifuged at $13,000 \mathrm{rpm}$ at $4^{\circ} \mathrm{C}$ for $15 \mathrm{~min}$, and the supernatant was collected as the nuclear fractions $(\mathrm{Nu})$.

\section{Lactate assay}

Cells were plated in 6-well plates, after the indicated treatments, suspension was collected and subjected to lactate assay. Levels of the secreted lactate were determined using the lactate assay kit (K-DATE, Megazyme). Data represent three independent experiments.

\section{Confocal/Fluorescence microscopy}

Cells were plated on glass cover slips and the indicated treatments were performed. Cells were washed with $\mathrm{Ca}^{2+}$ - and $\mathrm{Mg}^{2+}$-free PBS (CMF-PBS), fixed with freshly prepared $4 \%$ paraformaldehyde at $4{ }^{\circ} \mathrm{C}$ for $30 \mathrm{~min}$ and permeabilized incubation with CMF-PBS containing $0.1 \%$ Triton $\mathrm{X}-100$ and $0.5 \% \mathrm{BSA}$ at room temperature (RT) for $5 \mathrm{~min}$. Following washed three times with CMFPBS, cells were blocked in CMF-PBS containing 0.5\% BSA for $1 \mathrm{~h}$, and incubated with the indicated antibodies in the presence of $0.1 \%$ Triton X-100 and $0.5 \%$ BSA. After washed three times, cells were incubated with the secondary antibodies (Alexa Fluor ${ }^{\circledR} 594$ Goat antiRabbit and Alexa Fluor ${ }^{\circledR} 488$ Goat anti-Mouse) diluted in CMF-PBS containing 0.5\% BSA for $1 \mathrm{~h}$. Cells were then immersed in VECTASHIELD with DAPI (H1200) to visualize the nuclei after washing for three times. Images were acquired via Confocal/Fluorescence microscopy.

\section{Electron microscopy}

Briefly, samples were washed three times with PBS, trypsinized, and collected by centrifuging. Following fixed with $4 \%$ paraformaldehyde at $4{ }^{\circ} \mathrm{C}$ overnight, cell pellets were post-fixed with $1 \% \mathrm{OsO}_{4}$ in cacodylate buffer at RT for $1 \mathrm{~h}$, and dehydrated stepwise with ethanol. The dehydrated pellets were rinsed with propylene oxide at RT for $30 \mathrm{~min}$ and embedded in Spurr resin for sectioning. For immunoelectron microscopy, the frozen cells were treated with $0.2 \%$ glutaraldehyde and $2 \%$ distilled water in acetone, and embedded in LR white. Ultrathin sections were stained with anti-PFKFB3 antibody, and secondary antibodies conjugated to 10 -nm gold particles. Images of thin sections were observed under a transmission electron microscopy (JEM1230).

\section{Statistical analysis}

Several X-ray films were analyzed to verify the linear range of chemiluminescence signals and quantifications were carried out using densitometry. Adjusted ratios of the indicated proteins to actin (A) and changed folds for levels of LC3-II and p62 after expose to CQ were presented below the blots. Normally distributed data are shown as mean \pm SD and were analyzed using one-way analysis of variance and the Student-NewmanKeuls post-hoc test. Data are shown as Mean \pm SD in Graphs.

\section{Abbreviations}

ACC, acetyl-CoA carboxylase; AMPK, AMPactivated protein kinase; PFKFB3, 6-phosphofructo2-kinase/fructose-2,6-bisphosphatase isoform 3; PFK-1, phosphofructokinase-1; PFK-15, 1-(4-pyridinyl)3-(2-quinolinyl)-2-propen-1-one; Rapa, rapamycin; $\mathrm{CC}$, Compound C; AICAR, 5-Aminoimidazole-4carboxamide1- $\beta$-D-ribofuranoside.

\section{Author contributions}

$\mathrm{YC}, \mathrm{YZ}$ and $\mathrm{XJ}$ designed the research; $\mathrm{SY}$ and $\mathrm{XW}$ conducted the research; HS and WW prepared the cell samples for western blot assay; SX conducted the plasmids needed; LL helped during analyzing the data; SY and XJ wrote the manuscript; YC and YZ had primary responsibility for the final content. All authors read and approved the final manuscript.

\section{ACKNOWLEDGMENTS}

This work was supported by grants from the National Natural Science Foundation of China (31171329 and 31371403), National Program of Drug Research \& Development (2012ZX09301-003), and the Program of the Excellent Young Scientists of Chinese Academy of Sciences, and the Youth Innovation Promotion Association of Chinese Academy of Sciences (2011083).

\section{CONFLICTS OF INTEREST}

The authors declare no conflicts of interests.

\section{REFERENCES}

1. Ros S, Schulze A. Balancing glycolytic flux: the role of 6-phosphofructo-2-kinase/fructose 2,6-bisphosphatases in cancer metabolism. Cancer Metab. 2013; 1:8.

2. Warburg O. On the origin of cancer cells. Science. 1956; 123:309-314.

3. Vander Heiden MG, Cantley LC, Thompson CB. Understanding the Warburg effect: the metabolic requirements of cell proliferation. Science. 2009; 324:1029-1033.

4. Lunt SY, Vander Heiden MG. Aerobic glycolysis: meeting the metabolic requirements of cell proliferation. Annu Rev Cell Dev Biol. 2011; 27:441-464. 
5. TeSlaa T, Teitell MA. Techniques to monitor glycolysis. Methods Enzymol. 2014; 542:91-114.

6. Hue L, Rousseau GG. Fructose 2,6-bisphosphate and the control of glycolysis by growth factors, tumor promoters and oncogenes. Adv Enzyme Regul. 1993; 33:97-110.

7. Okar DA, Manzano A, Navarro-Sabate A, Riera L, Bartrons R, Lange AJ. PFK-2/FBPase-2: maker and breaker of the essential biofactor fructose-2,6-bisphosphate. Trends Biochem Sci. 2001; 26:30-35.

8. Atsumi T, Nishio T, Niwa H, Takeuchi J, Bando H, Shimizu C, Yoshioka N, Bucala R, Koike T. Expression of inducible 6-phosphofructo-2-kinase/fructose-2,6-bisphosphatase/ PFKFB3 isoforms in adipocytes and their potential role in glycolytic regulation. Diabetes. 2005; 54:3349-3357.

9. Xu Y, An X, Guo X, Habtetsion TG, Wang Y, Xu X, Kandala S, Li Q, Li H, Zhang C, Caldwell RB, Fulton DJ, Su Y, et al. Endothelial PFKFB3 plays a critical role in angiogenesis. Arterioscler Thromb Vasc Biol. 2014; 34:1231-39.

10. Yalcin A, Clem BF, Simmons A, Lane A, Nelson K, Clem AL, Brock E, Siow D, Wattenberg B, Telang S, Chesney J. Nuclear Targeting of 6-Phosphofructo-2-kinase (PFKFB3) Increases Proliferation via Cyclin-dependent Kinases. J Biol Chem. 2009; 284:24223-24232.

11. Klarer AC, O'Neal J, Imbert-Fernandez Y, Clem A, Ellis SR, Clark J, Clem B, Chesney J, Telang S. Inhibition of 6-phosphofructo-2-kinase (PFKFB3) induces autophagy as a survival mechanism. Cancer Metab. 2014; 2:2.

12. Yang Z, Fujii H, Mohan SV, Goronzy JJ, Weyand CM. Phosphofructokinase deficiency impairs ATP generation, autophagy, and redox balance in rheumatoid arthritis $\mathrm{T}$ cells. J Exp Med. 2013; 210:2119-2134.

13. Feng Y, He D, Yao Z, Klionsky DJ. The machinery of macroautophagy. Cell Res. 2014; 24:24-41.

14. Hardie DG. AMPK and autophagy get connected. EMBO J. 2011; 30:634-635.

15. Kim J, Kundu M, Viollet B, Guan KL. AMPK and mTOR regulate autophagy through direct phosphorylation of Ulk1. Nat Cell Biol. 2011; 13:132-141.

16. Shang LB, Wang XD. AMPK and mTOR coordinate the regulation of Ulk1 and mammalian autophagy initiation. Autophagy. 2011; 7:924-926.

17. Wullschleger S, Loewith R, Hall MN. TOR signaling in growth and metabolism. Cell. 2006; 124:471-484.

18. Mihaylova MM, Shaw RJ. The AMPK signalling pathway coordinates cell growth, autophagy and metabolism. Nat Cell Biol. 2011; 13:1016-1023.

19. Alers S, Loffler AS, Wesselborg S, Stork B. Role of AMPKmTOR-Ulk1/2 in the regulation of autophagy: cross talk, shortcuts, and feedbacks. Mol Cell Biol. 2012; 32:2-11.

20. Carling D, Mayer FV, Sanders MJ, Gamblin SJ. AMPactivated protein kinase: nature's energy sensor. Nat Chem Biol. 2011; 7:512-518.

21. Zhou G, Myers R, Li Y, Chen Y, Shen X, Fenyk-Melody J, Wu M, Ventre J, Doebber T, Fujii N, Musi N, Hirshman MF,
Goodyear LJ, Moller DE. Role of AMP-activated protein kinase in mechanism of metformin action. J Clin Invest. 2001; 108:1167-1174.

22. Gwinn DM, Shackelford DB, Egan DF, Mihaylova MM, Mery A, Vasquez DS, Turk BE, Shaw RJ. AMPK phosphorylation of raptor mediates a metabolic checkpoint. Mol Cell. 2008; 30:214-226.

23. Egan DF, Shackelford DB, Mihaylova MM, Gelino S, Kohnz RA, Mair W, Vasquez DS, Joshi A, Gwinn DM, Taylor R, Asara JM, Fitzpatrick J, Dillin A, et al. Phosphorylation of ULK1 (hATG1) by AMP-activated protein kinase connects energy sensing to mitophagy. Science. 2011; 331:456-461.

24. Overbye A, Fengsrud M, Seglen PO. Proteomic analysis of membrane-associated proteins from rat liver autophagosomes. Autophagy. 2007; 3:300-322.

25. Clem BF, O'Neal J, Tapolsky G, Clem AL, ImbertFernandez Y, Kerr DA, Klarer AC, Redman R, Miller DM, Trent JO, Telang S, Chesney J. Targeting 6-Phosphofructo2-Kinase (PFKFB3) as a Therapeutic Strategy against Cancer. Mol Cancer Ther. 2013; 12:1461-1470.

26. Creighton CJ, Morgan M, Gunaratne PH, Wheeler DA, Gibbs RA, Gordon Robertson A, Chu A, Beroukhim R, Cibulskis K, Signoretti S, Vandin Hsin-Ta Wu F, Raphael BJ, Verhaak RG, et al, and Cancer Genome Atlas Research Network. Comprehensive molecular characterization of clear cell renal cell carcinoma. Nature. 2013; 499:43-49.

27. Yla-Anttila P, Vihinen H, Jokitalo E, Eskelinen EL. Monitoring autophagy by electron microscopy in Mammalian cells. Methods Enzymol. 2009; 452:143-164.

28. Klionsky DJ, Abdelmohsen $\mathrm{K}$, Abe A, Abedin MJ, Abeliovich H, Acevedo Arozena A, Adachi H, Adams CM, Adams PD, Adeli K, Adhihetty PJ, Adler SG, Agam G, et al. Guidelines for the use and interpretation of assays for monitoring autophagy (3rd edition). Autophagy. 2016; 12:1-222.

29. Lu Q, Yan S, Sun H, Wang W, Li Y, Yang X, Jiang X, Che Y, $\mathrm{Xi}$ Z. Akt inhibition attenuates rasfonin-induced autophagy and apoptosis through the glycolytic pathway in renal cancer cells. Cell Death Dis. 2015; 6:e2005.

30. Tanida I, Minematsu-Ikeguchi N, Ueno T, Kominami E. Lysosomal turnover, but not a cellular level, of endogenous LC3 is a marker for autophagy. Autophagy. 2005; 1:84-91.

31. Cao DJ, Wang ZV, Battiprolu PK, Jiang N, Morales CR, Kong YL, Rothermel BA, Gillette TG, Hill JA. Histone deacetylase (HDAC) inhibitors attenuate cardiac hypertrophy by suppressing autophagy. Proc Natl Acad Sci USA. 2011; 108:4123-4128.

32. Apel K, Hirt H. Reactive oxygen species: metabolism, oxidative stress, and signal transduction. Annu Rev Plant Biol. 2004; 55:373-399.

33. Scherz-Shouval R, Elazar Z. ROS, mitochondria and the regulation of autophagy. Trends Cell Biol. 2007; $17: 422-427$. 
34. Zhang C, Yang L, Wang XB, Wang JS, Geng YD, Yang CS, Kong LY. Calyxin Y induces hydrogen peroxide-dependent autophagy and apoptosis via JNK activation in human nonsmall cell lung cancer NCI-H460 cells. Cancer Lett. 2013; 340:51-62.

35. D'Amours D, Desnoyers S, D'Silva I, Poirier GG. Poly(ADP-ribosyl)ation reactions in the regulation of nuclear functions. Biochem J. 1999; 342:249-268.

36. Dou Z, Xu C, Donahue G, Shimi T, Pan JA, Zhu J, Ivanov A, Capell BC, Drake AM, Shah PP, Catanzaro JM, Ricketts MD, Lamark T, et al. Autophagy mediates degradation of nuclear lamina. Nature. 2015; 527:105-109.

37. Workman JL, Kingston RE. Alteration of nucleosome structure as a mechanism of transcriptional regulation. Annu Rev Biochem. 1998; 67:545-579.

38. Rodriguez-Rodriguez P, Fernandez E, Almeida A, Bolanos JP. Excitotoxic stimulus stabilizes PFKFB3 causing pentose-phosphate pathway to glycolysis switch and neurodegeneration. Cell Death Differ. 2012; 19:1582-1589.

39. Ha J, Daniel S, Broyles SS, Kim KH. Critical phosphorylation sites for acetyl-CoA carboxylase activity. J Biol Chem. 1994; 269:22162-22168.

40. Favero CB, Mandell JW. A pharmacological activator of AMP-activated protein kinase (AMPK) induces astrocyte stellation. Brain Res. 2007; 1168:1-10.

41. Vucicevic L, Misirkic M, Janjetovic K, Vilimanovich U, Sudar E, Isenovic E, Prica M, Harhaji-Trajkovic L, KravicStevovic T, Bumbasirevic V, Trajkovic V. Compound C induces protective autophagy in cancer cells through AMPK inhibition-independent blockade of Akt/mTOR pathway. Autophagy. 2011; 7:40-50.

42. Hoyer-Hansen M, Bastholm L, Szyniarowski P, Campanella M, Szabadkai G, Farkas T, Bianchi K, Fehrenbacher N, Elling F, Rizzuto R, Mathiasen IS, Jaattela M. Control of macroautophagy by calcium, calmodulin-dependent kinase kinase-beta, and Bcl-2. Mol Cell. 2007; 25:193-205.

43. Hoyer-Hansen M, Jaattela M. AMP-activated protein kinase - A universal regulator of autophagy? Autophagy. 2007; 3:381-383.
44. Mendoza EE, Pocceschi MG, Kong X, Leeper DB, Caro J, Limesand KH, Burd R. Control of Glycolytic Flux by AMPActivated Protein Kinase in Tumor Cells Adapted to Low pH. Transl Oncol. 2012; 5:208-216.

45. Almeida A, Moncada S, Bolanos JP. Nitric oxide switches on glycolysis through the AMP protein kinase and 6-phosphofructo-2-kinase pathway. Nat Cell Biol. 2004; 6:45-51.

46. Doménech E, Maestre C, Esteban-Martínez L, Partida D, Pascual R, Fernández-Miranda G, Seco E, Campos-Olivas R, Pérez M, Megias D, Allen K, López M, Saha AK, et al. AMPK and PFKFB3 mediate glycolysis and survival in response to mitophagy during mitotic arrest. Nat Cell Biol. 2015; 17:1304-1316.

47. Mendoza MC, Er EE, Blenis J. The Ras-ERK and PI3KmTOR pathways: cross-talk and compensation. Trends Biochem Sci. 2011; 36:320-328.

48. Loffler AS, Alers S, Dieterle AM, Keppeler H, FranzWachtel M, Kundu M, Campbell DG, Wesselborg S, Alessi DR, Stork B. Ulk1-mediated phosphorylation of AMPK constitutes a negative regulatory feedback loop. Autophagy. 2011; 7:696-706.

49. Tao R, Gong J, Luo X, Zang M, Guo W, Wen R, Luo Z. AMPK exerts dual regulatory effects on the PI3K pathway. J Mol Signal. 2010; 5:1.

50. Habib SL, Kasinath BS, Arya RR, Vexler S, Velagapudi C. Novel mechanism of reducing tumourigenesis: upregulation of the DNA repair enzyme OGG1 by rapamycin-mediated AMPK activation and mTOR inhibition. Eur J Cancer. 2010; 46:2806-2820.

51. Guilbert C, Annis MG, Dong Z, Siegel PM, Miller WH, Jr., Mann KK. Arsenic trioxide overcomes rapamycin-induced feedback activation of AKT and ERK signaling to enhance the anti-tumor effects in breast cancer. PLoS One. 2013; 8:e85995. 